\title{
An overview of the tobacco problem in India
}

\author{
Gauravi A. Mishra, \\ Sharmila A. Pimple, \\ Surendra S. Shastri \\ Department of Preventive \\ Oncology, Tata Memorial Hospital, \\ E. Borges Marg, Parel, Mumbai, \\ India
}

\author{
Address for correspondence: \\ Dr. Gauravi A. Mishra, \\ Department of Preventive \\ Oncology, Tata Memorial Hospital, \\ E. Borges Marg, Parel, \\ Mumbai - 400012 , \\ Maharashtra, India. \\ E-mail: gauravi2005@yahoo.co.in
}

\begin{abstract}
A B S T R A C T
This is a review paper comprehensively encompassing the different aspects of tobacco control with particular reference to the Indian scenario. The information on prevalent tobacco habits in India, health hazards and environmental hazards due to tobacco use, passive smoking and its impact, economics of tobacco, legislation to control tobacco in India, the tobacco cessation services and the way ahead for effective tobacco control are discussed. Tobacco is a leading preventable cause of death, killing nearly six million people worldwide each year. Reversing this entirely preventable manmade epidemic should be our top priority. This global tobacco epidemic kills more people than tuberculosis, HIV/AIDS and malaria combined. This epidemic can be resolved by becoming aware of the devastating effects of tobacco, learning about the proven effective tobacco control measures, national programmes and legislation prevailing in the home country and then engaging completely to halt the epidemic to move toward a tobacco-free world. India is the second largest consumer of tobacco globally, and accounts for approximately one-sixth of the world's tobacco-related deaths. The tobacco problem in India is peculiar, with consumption of variety of smokeless and smoking forms. Understanding the tobacco problem in India, focusing more efforts on what works and investigating the impact of sociocultural diversity and cost-effectiveness of various modalities of tobacco control should be our priority.
\end{abstract}

Key words: Cigarettes and other tobacco products act, framework convention on tobacco control, hazards of tobacco, tobacco control, national tobacco control program

\section{INTRODUCTION}

Tobacco use kills nearly six million people worldwide each year. According to the World Health Organization (WHO) estimates, globally, there were 100 million premature deaths due to tobacco in the $20^{\text {th }}$ century, and if the current trends of tobacco use continue, this number is expected to rise to 1 billion in the $21^{\text {st }}$ century. ${ }^{[1]}$

Jha et al. have estimated that around 1 million deaths a year in India will be attributable to smoking by the early 2010s. ${ }^{[2]}$ Gupta et al. have estimated the tobacco-attributable mortality among Indian men and women from their Mumbai cohort study. Based on these estimates, nearly $23.7 \%$ of the deaths among men $(527,500)$ and $5.7 \%$ of the deaths among women $(83,000)$ aged 35-69 years are due to tobacco-attributable illnesses. ${ }^{[3]}$ Another cohort

\begin{tabular}{|l|l|}
\hline \multicolumn{3}{c|}{ Access this article online } \\
\hline Quick Response Code: & Website: \\
\hline & www.jimpo.org \\
\hline
\end{tabular}

study from southern India reported mortality risks of 0.98 (0.86-0.94) and 1.22 (1.04-1.44) for all-cause and tobaccorelated cancer mortality, respectively, for tobacco chewing, while with smoking, the respective mortality risks were 1.31 $(1.24-1.39)$ and $1.68(1.36-2.08) .^{[4]}$

According to the National Family Health Survey (NFHS)3 survey, conducted in 2005-06, tobacco use is more prevalent among men, rural population, illiterates, poor and vulnerable section of the society. ${ }^{[5]}$ The estimates of the Global Adult Tobacco Survey (GATS) conducted among persons 15 years of age or older during 2009-10 indicate that $34.6 \%$ of the adults ( $47.9 \%$ males and $20.3 \%$ females) are current tobacco users. Fourteen percent of the adults smoke $(24.3 \%$ males and $2.9 \%$ females $)$ and $25.9 \%$ use smokeless tobacco $\left(32.9 \%\right.$ males and $18.4 \%$ females ${ }^{[6]}$ According to the Global Youth Tobacco Survey (GYTS) conducted among 24,000 students aged 13-15 years in $2009,14.6 \%$ students were tobacco users. ${ }^{[7]}$

India's tobacco problem is very complex, with a large use of a variety of smoking forms and an array of smokeless tobacco products. Many of these products are manufactured as cottage and small-scale industries using varying mixtures and widely differing processes of manufacturing. ${ }^{[8]}$ Bidis 
are mostly manufactured in the unorganized sector while cigarettes are mainly manufactured in large-scale industries.

\section{HAZARDS OF TOBACCO USE}

\section{Health}

Tobacco is deadly in any form or disguise. Scientific evidence has unequivocally established that exposure to tobacco smoke causes death, disease and disability. ${ }^{[0]}$ According to the International Agency for Research on Cancer (IARC) monograph, there is sufficient evidence in humans that tobacco smoking causes cancer of the lung, oral cavity, naso-, oro- and hypo-pharynx, nasal cavity and paranasal sinuses, larynx, esophagus, stomach, pancreas, liver, kidney (body and pelvis), ureter, urinary bladder, uterine cervix and bone marrow (myeloid leukemia). Colorectal cancer is seen to be associated with cigarette smoking, although there is insufficient evidence for it to be causal. ${ }^{[10]}$ Ninety percent of all lung cancer deaths in men and $80 \%$ in women are caused by smoking. ${ }^{[9]}$ Causal associations have been clearly established between active smoking and adverse reproductive outcomes, chronic obstructive pulmonary disease and cardiovascular diseases. ${ }^{[10]}$ Studies on bidi smoking, the most common form of tobacco smoking in India, provide evidence toward causality of it as carcinogenic substance. Case-control studies demonstrate a strong association of bidi smoking with cancers at various sites, such as oral cavity (including subsites), pharynx, larynx, esophagus, lung and stomach. Almost all studies show significant trends with duration of bidi smoking and number of bidis smoked. ${ }^{[10]}$ Forty percent of the tuberculosis burden in India may be attributed to smoking. Significant association is seen between passive or active exposure to tobacco smoke and tuberculous infection, disease and tuberculosis mortality. ${ }^{[1]}$ Smoking was associated with excess deaths among smokers between 30 and 69 years, mainly from tuberculosis and also from respiratory, vascular or neoplastic disease. ${ }^{[2]}$ The risk of tuberculosis deaths among bidi smokers was 2.60-times higher than never-smokers in Mumbai. ${ }^{[12]}$ Workers engaged in tobacco cultivation suffer from an occupational illness known as green tobacco sickness (GTS), an acute form of nicotine toxicity resulting from absorption of nicotine through the skin. ${ }^{[8]}$

Pednekar et al. in their Mumbai cohort found that the incidence of oral cancers was $42 \%$ higher among bidi smokers as compared with cigarette smokers. ${ }^{[13]}$ Smokeless tobacco use was associated with cancers of the lip, oral cavity, pharynx, digestive, respiratory and intrathoracic organs. ${ }^{[13]} \mathrm{A}$ study in North India showed a significant association of chewing tobacco and oral cancer with direct relation between quantity and duration of use. ${ }^{[14]}$ India has one of the highest rates of oral cancer in the world, with over $50 \%$ attributable to smokeless tobacco use. ${ }^{[15]}$

There is sufficient evidence in humans for the carcinogenicity of smokeless tobacco. Several studies have established a causal association between use of smokeless tobacco and cancers of oral cavity, esophagus and pancreas. Smokeless tobacco causes acute increases in blood pressure and heart rate, and has been associated with a small increase of cardiovascular disease risk. Effects on insulin sensitivity, glucose tolerance and the risk for diabetes from smokeless tobacco use are plausible. ${ }^{[16]}$ The use of smokeless tobacco causes reproductive and developmental toxicity, and its use during pregnancy increases the risks for preeclampsia and premature birth, causes increased placental weight and reduces mean birth weight. Smokeless tobacco use by men causes reduced semen volume, reduced sperm count, reduced sperm motility and an increased frequency of abnormal spermatozoa. ${ }^{[16]}$

\section{Environment}

Tobacco leads to clearing of forests for cultivation, stripping fuel wood for curing and forest resources for packaging thus damaging the environment. Tobacco depletes the soil nutrients at a very rapid rate and displaces the indigenous flora and fauna thus becoming a source of pests for other crops. ${ }^{[8]}$

\section{Passive smoking}

Second-hand tobacco smoke (SHS) kills 600,000 people each year. Globally, about one-third adults are regularly exposed to SHS. The GATS-India shows that $52 \%$ of the adults (rural-58\%, urban-39\%) were exposed to SHS at home. ${ }^{[6]}$ SHS is three- to four-times more toxic per gram of particulate matter than mainstream tobacco smoke. More than 4000 chemicals have been identified in tobacco smoke, at least 250 of which are known to be harmful. Toxic chemicals from SHS cling to rugs, curtains, clothes, food, furniture and other materials. These toxins remain even in the presence of windows, fans or air filters, and can recycle back into the air through the filters. They coat the surfaces of rooms, materials and smoker's belongings, and are sometimes referred to as "third-hand smoke." [17] There is conclusive evidence linking passive smoking to an increased risk of cardiovascular diseases, lung cancer and other cancers, asthma and other respiratory diseases in adults and asthma and other respiratory diseases, ear infection and sudden infant death syndrome in children, to name but a few of passive smoking's harmful effects. ${ }^{[8,17]}$

\section{LEGISLATION AND ENFORCEMENT}

\section{WHO framework convention on tobacco control}

Legislation is recognized as the critical driver for meaningful progress in tobacco control. The WHO framework 
convention on tobacco control (WHO FCTC) is a global public health treaty developed as a global response to the globalization of the tobacco epidemic, which aims at reducing the burden of disease and death caused by tobacco. It was adopted by the World Health Assembly in May 2003, and India was the eighth country to ratify it on 5 February 2004. The FCTC embraces scientific evidencebased approaches that have shown effectiveness in reducing tobacco consumption. It does not lay down a law, but sets out guidelines for various national and international measures that would encourage smokers to quit and restrain nonsmokers from taking the habit. The success of the WHO FCTC, which as of July 2009 had more than 160 parties covering $86 \%$ of the world's population, demonstrates the global political will for making tobacco control far more comprehensive and successful. ${ }^{[18]}$ The WHO has established the MPOWER package to help countries comply with the WHO FCTC. This is a package encompassing six most important and effective tobacco control policies: Monitoring tobacco use and prevention policies, Protecting people from tobacco smoke, Offering help to people to quit tobacco use, Warning everyone about the dangers of tobacco, Enforcing ban on tobacco advertising, promotion and sponsorship and Raising taxes on tobacco. ${ }^{[1]}$

In India, since 1975, it is mandatory to display a statutory health warning on all packages and advertisements of cigarettes because of the Cigarettes (Regulation of Production, Supply and Distribution) Act, enacted by the Government of India (GOI). Further restrictions on tobacco trade were initiated along with efforts to bring forth a comprehensive legislation for tobacco control during the 1980s and 1990s. The Indian Parliament passed the Cigarettes and Other Tobacco Products (Prohibition of Advertisement and Regulation of Trade and Commerce, Production, Supply and Distribution) Bill, 2003 in April 2003. This Bill became an Act on 18 May 2003 - COTPA. ${ }^{[1]}$ Rules were formulated and enforced from 1 May 2004. The Act is applicable to all products containing tobacco in any form, and extends to the whole of India.

The key provisions of COTPA -2003 are as follows:

- Prohibition of smoking in public places (including indoor workplaces). This has been implemented from $2^{\text {nd }}$ October 2008 in the whole of India.

- Prohibition of advertisement, direct and indirect (point-of-sale advertising is permitted), sponsorship and promotion of tobacco products.

- Prohibition of sales to minors (tobacco products cannot be sold to children less than 18 years of age and cannot be sold within a radius of 100 yards of any educational institutions).

- Regulation of health warning in tobacco products packs. English and one more Indian language to be used for health warnings on tobacco packs. Pictorial health warnings also to be included.

- Regulation and testing of tar and nicotine contents of tobacco products and declaring on tobacco products packages.

\section{National tobacco control programme}

The Ministry of Health and Family Welfare (MHFW), GOI, has launched the National tobacco control programme (NTCP $)^{[19]}$ in the XI Five Year Plan to facilitate the implementation of the Tobacco Control Laws, bring about greater awareness about the harmful effects of tobacco and to fulfill the obligations under the WHO-FCTC. The Cabinet Committee on Economic Affairs (CCEA) on 28 January 2010 approved the programme. The NTCP will establish tobacco product testing laboratories, provide baseline estimates of tobacco prevalence and status of implementation of the Tobacco Control Law. The pilot phase will focus on 42 districts of 21 states. $^{[19]}$ The activities of NTCP are arranging exhibitions, seminars, banners at District level, implementing the anti-tobacco act in letter and spirit, sending monthly reports regarding the anti-tobacco activities in the district level to the state. At the headquarters the activities focused are promoting Information, Education and Communication (IEC) activities at the district level and multi-sectoral involvement for the implementation of the Act with the help of NGOs, Police Department, Education Department and the Local Administration.

Numerous voluntary organizations like the HRIDAYSHAN, CPAA-Cancer patients aids association, the Salaam Mumbai Foundation, HealthBridge, Voluntary Health Association of India, etc. are actively involved in tobacco control activities in India. Healis is actively engaged in conducting quality research in tobacco control. In addition, it is involved in media mobilization for tobacco control, public education, conducting workshops for different stake holders and conducting scientific conferences and meetings of national and international level. ${ }^{[20]}$ The Public Health Foundation of India (PHFI) has launched a multi-faceted website to create an enabling environment for tobacco control in the country. The web portal comprehensively offers training, resources and research evidence with regard to tobacco control. ${ }^{[21]}$ To support global efforts for tobacco control, The Union focuses on several key policies that are proven to reduce tobacco consumption. In India, the Union has been active in collaborating with the central and state governments and prominent NGOs to strengthen pack warning content and its implementation. The WHO is actively involved in tobacco control in India. Tobacco surveillance has been included in the integrated disease surveillance programme. ${ }^{[2]}$ A National Tobacco Control 
Cell was set up by the WHO in collaboration with the Ministry of Health and Family Welfare, which has activities in the different spheres of tobacco control, with the main impetus on spreading awareness. ${ }^{[23]}$

\section{TOBACCO CESSATION SERVICES}

There are several policy measures of tobacco control being implemented at the national and international level to fight the battle against tobacco. However, these efforts may not directly benefit the current tobacco user as nicotine in tobacco is very addictive, making quitting difficult. It has been estimated that a lack of cessation services may lead to an additional 160 million global deaths among smokers by 2050 . A majority of tobacco users (nearly $70 \%$ ) wish to quit the habit, but only $3-5 \%$ actually succeed in doing so. The WHO in collaboration with the MHFW, GOI, set up 13 tobacco cessation centers (TCC) in 2002 spread across India in diverse settings (cancer treatment centers, psychiatric centers, medical colleges and NGOs) to help people quit tobacco. This number has now increased to 19. The WHO algorithm for tobacco cessation ${ }^{[24]}$ consists of assessing the tobacco habit and then going through the procedures of simple advice, behavioral counseling and pharmaceutical treatment as per requirement.

Simple advice by health professional, taking as little as $30 \mathrm{~s}$, can produce quit rates of 5-10\% per year. Every patient who uses tobacco should be offered a brief intervention method of 5 A's, ASK (about tobacco use)- ADVISE (to quit) - ASSESS (commitment and barriers to change) - ASSIST (users committed to change) - ARRANGE (follow-up to monitor progress). The tobacco user's readiness to change can be assessed by the trans-theoretical model of Prochaska and Di Clemente, wherein the stages of change are noted as precontemplation, contemplation, preparation, action, maintenance and termination. Specific interventions are then tailored as per the person's stage of change in order to increase the likelihood of the success of quitting.

Pharmacological interventions when used with behavioral strategies can produce quit rates of about $25-30 \%$. Pharmacotherapies that reliably increase the long-term smoking abstinence rates include:

a. Agents that appear to decrease craving - Bupropion, Selegeline, Nortryptiline, etc.

b. Agents that are used to substitute the nicotine, obtained from tobacco - Nicotine gum, Nicotine patch, Nicotine inhaler or Nicotine nasal spray. Nicotine Replacement Therapy (NRT) provides a slow and steady supply of nicotine in order to relieve craving and withdrawal symptoms, and is associated with quit rates of about $23 \%$ as against $13 \%$ with placebo.
TCCs from India have reported overall quit rates of around $16 \%$ at 6 weeks postintervention. The major disadvantages of a clinic approach of TCCs are its reach to specific population and loss to follow-up. Repeated contact counseling is a key to the success of cessation and prevention of relapses. Hence, expansion beyond clinics is the need of the hour to meet the needs of millions of current tobacco users in India. This can be in the form of community outreach clinics, interventions provided at schools, colleges, workplaces, youth groups, women's groups, etc. Spontaneous peer groups may be formed within the community, which may further support an individual's decision to quit. The workplace is an excellent setting to conduct a tobacco cessation progamme as it gives an opportunity to interact with large number of people simultaneously, helps to train the industrial medical staff in tobacco cessation activities, promises positive peer pressure and a stable population for follow-up. Several cessation activities have been conducted at a variety of workplaces in both urban and rural India, demonstrating a good quit rate. ${ }^{[25,26]}$ This method needs to be explored further.

Other methods of cessation, like the group counseling, behavioral interventions in adolescents and pregnant women, technology-driven interventions, such as telephone counseling, dedicated quitlines, and mobile and web-based technologies have recently gained popularity. Combining different interventions gives good results as compared with a single intervention. ${ }^{[27]}$

\section{THE ECONOMICS OF TOBACCO}

The economic contribution of the tobacco industry

The tobacco industry claims that it has a major contribution to economy with its employment generation in agriculture and manufacturing and revenues in the form of exports and taxes. Economic measures to reduce tobacco use that are part of a comprehensive tobacco control program can counteract these. ${ }^{[28]}$ In 2009, India was the third largest producer of tobacco in the world. It produced 620,000 (MT) of tobacco worth 987,513 (Int $\$ 1000$ ) in 2009. India exported 230,804 tonnes of unmanufactured tobacco, with a worth value of $748,553(\$ 1000)$ in 2009. ${ }^{[29]}$

According to the World Bank Report, the tobacco industry estimates that 33 million people are engaged in tobacco farming, of which 3.5 million are in India. ${ }^{[30]}$ Many women and children manufacture bidis and various forms of smokeless tobacco products working from home. It is estimated that bidi manufacturing provides employment to more than 4.4 million workers. ${ }^{[31]}$ Alternate cropping and alternate livelihoods need to be provided by the Government to replace tobacco farming and employment in the tobacco products manufacturing. In India, four major 
cigarette players dominate the cigarette market worth an estimated 60 billion rupees viz. Indian Tobacco Company (ITC), Godfrey Phillips Limited, Golden Tobacco and National Tobacco. ${ }^{[30]}$ Bidis still remain a major tobacco market, with a predicted sale of 1031 billion bidis in $2007^{[32]}$ Smokeless tobacco products like Gutkha and pan masala are available in attractive colorful small sachets for as low as half a rupee, and have become increasingly popular with aggressive marketing and advertisements.

In India, tobacco export is mainly unmanufactured. Excise duty is imposed on the entire range of manufactured tobacco products, although the major contribution is from cigarettes. In 2000-01, tobacco contributed Rs. 81,820 million to the Indian economy and accounted for about $12 \%$ of the total excise collections. ${ }^{[33]}$ Bidi manufacturers producing less than 2 million pieces annually do not have to pay any excise duty. Pan masala is taxed $40 \%$ excise duty (ad valorem) and chewing tobacco and snuff with a brand name attracts $50 \%$ excise duty (ad valorem). ${ }^{[31]}$

\section{The economic losses due to the tobacco industry}

Tobacco inflicts high direct and indirect costs on the society due to the morbidity and mortality associated with the consumption of tobacco products. According to the Indian Council of Medical Research, the total losses in 1999 due to tobacco-related diseases were about Rs 277.6 billion, equivalent to US $\$ 6.5$ billion. The estimates were Rs 350,000 for cancer, Rs 29,000 for coronary artery disease and over Rs. 23,000 for chronic obstructive lung disease. ${ }^{[34]}$ The estimated total cost by Reddy and Gupta for the three major tobacco-related diseases for the year 2002-03 is Rs 308.33 (\$6.6) billion. ${ }^{[8]}$ John et al. estimated the total economic cost of tobacco use in India in 2004 to be $\$ 1.7$ billion, which is $16 \%$ more than the total excise tax revenues collected from all tobacco products in the financial year 2003-04 (\$1.46 billion). This includes the direct medical costs of treating tobacco-related diseases, which was $\$ 907$ million for smoked tobacco and $\$ 285$ million for smokeless tobacco. They also calculated the indirect morbidity costs of tobacco use, which included the cost of caregivers and value of work loss due to illness. This amounted to $\$ 398$ million for smoked tobacco and $\$ 104$ million for smokeless tobacco. Tuberculosis accounted for $18 \%$ of tobaccorelated costs (\$311 million) in India. ${ }^{[35]}$

\section{The cost-effectiveness of tobacco control and impact of tobacco control policies}

Ranson et al. have shown that overall tax increases on cigarettes is more cost-effective relative to other health interventions. ${ }^{[36]}$ The evidence mainly emerging from the developed countries suggests that a $10 \%$ increase in cigarette prices would result in a $2.5-5 \%$ reduction in cigarette demand. ${ }^{[37]}$ The evidence on price responsiveness from low- and middle-income countries has recently become available, suggesting that the impact is at least as large, and likely larger, than its impact in high-income countries. ${ }^{[28]}$ A price increase of $10 \%$ would reduce smoking by about $4 \%$ in high-income countries and by about $8 \%$ in low-income and middle-income countries. ${ }^{[38]}$ The 2002 estimates for China concluded that a $10 \%$ increase in cigarette prices would decrease cigarette consumption by up to $5.4 \%$ in the short run and by up to $6.6 \%$ in the long run. ${ }^{[39]}$ An all-India pooled sample report suggests that a $10 \%$ increase in bidi prices could reduce rural bidi consumption by $9.2 \%$ and a $10 \%$ increase in cigarette prices could reduce rural cigarette consumption by $3.4 \% .{ }^{[40]}$

Studies estimating the price responsiveness of cigarette demand to cigarette prices found that young people and lower-income groups are the most price-responsive. ${ }^{[28]}$ A study from Vietnam concluded that higher cigarette prices may not necessarily encourage quitting and may only divert cigarette smokers to other tobacco products. ${ }^{[41]}$ However, it is expected that increases in tobacco taxes reduce tobacco use by preventing initiation, increasing the likelihood of cessation among current users, reducing relapse among former users and reducing consumption among continuing users. It is clear that significant increases in tobacco taxes would be very effective in reducing tobacco use in low- and middle-income countries and, hence, it may be the most effective method of tobacco control in India. ${ }^{[42]}$ However, more research is certainly warranted in the Indian setting, both urban and rural, to investigate the cost-effectiveness of various modalities of tobacco control. In the context of several developing economies, further research would be needed to assess the possible impact of tobacco taxation on tobacco smuggling, substituting to other rustic tobacco products and on indigenous local tobacco production post taxation.

Various studies have shown that raising tobacco taxes leading to reduction in consumption is compensated by increased tobacco tax. Higher tobacco taxation improves public health by reducing tobacco use, and thereby helps a country generate additional revenue and reduce expenditures on the treatment of tobacco-related diseases. ${ }^{[43,44]}$ Indian projections suggest that tax-induced price increases of $52.8 \%$ on bidis and $176 \%$ on cigarettes would have a positive impact both on public revenue via taxes (expected to generate Rs 36.9 billion - US $\$ 0.8$ billion and Rs 146.3 billion - US\$ 3.1 billion) and on reduced tobacco-related public health expenditures. ${ }^{[40]}$

\section{WHAT WORKS FOR TOBACCO CONTROL?}

There is strong evidence that tobacco tax increases, the 
dissemination of information about the health risks from tobacco and increased access to cessation therapies are effective in reducing tobacco use. However, their implementation is uneven and limited, with higherincome countries having more anti-smoking laws in place than the low- and middle-income countries. ${ }^{[45]}$ Effective implementation may be affected by the tobacco industry lobbying power, partly due to political constraints and the country's overall commitment to tobacco control. ${ }^{[46]}$ The International Tobacco Control Policy Evaluation Project (ITC Project) ${ }^{[47]}$ designed to evaluate the impact of policies implemented under WHO FCTC will provide further evidence base to guide policies enacted under the FCTC and systematically evaluate the effectiveness of these legislative efforts.

\section{THE WAY AHEAD}

Measures that proved very effective in the developed world, like tax increases on all tobacco products, need to be enforced immediately and the taxes collected should be used to support health promotion and tobacco control programmes. Sustained efforts are needed from the Government to strengthen efforts on alternate cropping and alternate livelihoods to replace employment losses that may come up gradually.

Public health awareness, raising a mass movement against tobacco, sensitizing and educating all health care professionals for tobacco control and cessation by incorporating the topic in medical undergraduate curriculum, nursing curriculum, various CMEs, conferences, scientific meetings, workshops, etc. is vital. Eventually, if all healthcare professionals participate in tobacco control and cessation, it will have a huge impact. Expansion of TCCs to the periphery to reach the community, making them more accessible and widely acceptable, will facilitate millions of current tobacco users to quit the habit.

\section{REFERENCES}

1. WHO Report on The Global Tobacco Epidemic, 2011. The MPOWER packge, warning about the dangers of tobacco. Geneva: WHO; 2011.

2. Jha P, Jacob B, Gajalakshmi V, Gupta PC, Dhingra N, Kumar R, et al. A nationally representative case-control study of smoking and death in India. N Engl J Med 2008;358:1137-47.

3. Gupta PC, Pednekar MS, Parkin DM, Sankaranarayanan R. Tobacco associated mortality in Mumbai (Bombay) India. Results of the Bombay Cohort Study. Int J Epidemiol 2005;34;1395-402.

4. Ramadas K, Sauvaget C, Thomas G, Fayette JM, Thara S, Sankaranarayanan R. Effect of tobacco chewing, tobacco smoking and alcohol on all-cause and cancer mortality: A cohort study from Trivandrum, India. Cancer Epidemiol 2010;34,4:405-12.

5. International Institute for Population Sciences (IIPS) and
Macro International. 2007. National Family Health Survey (NFHS-3), 2005-06: India: Volume I. Mumbai: IIPS. Morbidity and Health Care; 2007. p. 426-8.

6. Global Adult Tobacco Survey (GATS) India: 2009-2010 available from: http://www.searo. who.int/LinkFiles/Regional Tobacco_Surveillance_System_GATS_India.pdf publishē by IIPS, Mumbai and funded by the Ministry of Health and Family Welfare, GOI 2010. [Last accessed on 2011 Jun 17].

7. Gajalakshmi V, Kanimozhi CV. A Survey of 24,000 Students Aged 13-15 Years in India: Global Youth Tobacco Survey 2006 and 2009. Tobacco Use Insights 2010:3:23-3.

8. Report on Tobacco Control in India (New Delhi, India), In: Reddy KS, Gupta PC, Editors, New Delhi, India: Ministry of Health and Family Welfare; 2004.

9. A global epidemic of addiction and disease. Tobacco: deadly in any form or disguise. World Health Organization. WHO Tobacco Free Initiative. ISBN 9241563222 (NLM classification: QV 137) ISBN 978924156322 World No Tobacco Day 2006. Available from: http://www. who.int/tobacco/communications/events/wntd/2006/ Report_v8_4May06.pdf [Last accessed on 2011 Jun 17].

10. Tobacco Smoke and Involuntary Smoking. IARC Monographs on the Evaluation of Carcinogenic Risks to Humans. IARC; 2002. p. 83.

11. A WHO / The Union monograph on TB and tobacco control: Joining efforts to control two related global epidemics. 2007 p. 8-10.

12. Pednekar MS, Gupta PC. Prospective study of smoking and tuberculosis in India. Prev Med 2007;44:496-8.

13. Pednekar MS, Gupta PC, Yeole BB, Hébert JR. Association of tobacco habits, including bidi smoking, with overall and sitespecific cancer incidence: Results from the Mumbai cohort study. Cancer Causes Control 2011;22:859-68.

14. Goud ML, Mohapatra SC, Mohapatra P, Gaur SD, Pant GC, Knanna MN. Epidemiological Correlates between Consumption of Indian Chewing Tobacco and Oral Cancer. Eur J Epidemiol $1990 ; 6,2: 219-22$.

15. Boffetta P, Hecht S, Gray N, Gupta P, Straif K. Smokeless tobacco and cancer. Lancet Oncol 2008;9:667-75.

16. Smokeless Tobacco. IARC Monograph. monographs.iarc.fr/ ENG/Monographs/vol89/mono89-6.pdf

17. WHO Report on The Global Tobacco Epidemic, 2009. Implementing smoke-free environments. fresh and alive mpower, WHO 2009.

18. WHO Framework Convention on Tobacco Control. World Health Organization. 2003 (updated reprint 2005) ISBN 978 9241591010.

19. Ministry of health and Family Welfare, Government of India. Available from: http://www.mohfw.nic.in/National\%20 Programme\%20for\%20Tobacco\%20Control.htm [Last accessed on 2010 Nov 06].

20. Available from: http://www.healis.org/ [Last accessed on 2011 Nov 17]

21. Available from: http://www.phfi.org/ [Last accessed on 2011 Nov 17].

22. Available from: http://www.tobaccofreeunion.org/content/ en/393/ [Last accessed on 2011 Nov 19].

23. Available from: http://whoindia.org/en/section20/ section25_925.htm [Last accessed on 2011 Nov 19].

24. Manual for Tobacco Cessation. National Cancer Control Programme. Directorate General of Health Services. Government of India: Ministry of Health and Family Welfare; 2005.

25. Mishra GA, Majmudar PV, Gupta SD, Rane PS, Hardikar NM, Shastri SS. Call Centre Employees and Tobacco Dependence - Making a Difference. Indian J Cancer 2010;47,5:43-52.

26. Mishra GA, Majmudar PV, Gupta SD, Rane PS, Uplap PA, Shastri SS. Workplace tobacco cessation program in India: A success story. Indian J Occup Environ Med 2009;13: 146-53. 
27. Murthy $\mathrm{P}$, Saddichha $\mathrm{S}$. Tobacco cessation services in India: Recent developments and the need for expansion. Indian $\mathrm{J}$ Cancer 2010;47:69-74.

28. Ross H, Chaloupka FJ. Economic policies for tobacco control in developing countries; salud pública de méxico 2006;48:113-20.

29. Food and agriculture organization of the United Nations. FAO available from: http://faostat.fao.org/site/339/default.aspx [Last accessed on 2011 Nov 19].

30. Development in Practice. Curbing the Epidemic. Government and the Economics of Tobacco Control. Washington, DC: A World Bank Publication; 1999.

31. Tobacco in India. FAO Corporate Document Repository ISSN 1810-0783. Produced by Economic and Social development department. Issues in the Global tobacco Economy. United Nations Rome, 2003 available from: http://www.fao.org/ docrep/006/y4997e/y4997eOh.htm\#TopOfPage [Last cited on 2011 Jun 17].

32. Shimkhada R, Peabody JW. Tobacco control in India. Bull World Health Organ 2003;81:48-52.

33. Rao V, Chaturvedi P. Tobacco and health in India. Indian Journal of Cancer 2010;47,5:3-8.

34. Rath GK, Chaudhry K. Estimation of cost of management of tobacco related cancers Report of an ICMR Task Force Study (1990-1996).New Delhi, India: Institute of Rotary Cancer Hospital, All India Institute of Medical Sciences; 1999.

35. John RM, Sung HY, Max W. Economic cost of tobacco use in India, 2004. Tob Control 2009;18:138-43.

36. Ranson MK, Jha P, Chaloupka FJ, Nguyen SN. Global and regional estimates of the effectiveness and cost-effectiveness of price increases and other tobacco control policies. Nicotine Tob Res 2002;4:311-9.

37. Chaloupka FJ, Warner KE. The economics of smoking. In: Newhouse JP, Cuyler AJ, editors. The handbook of health economics. New York: North-Holland; 2000.

38. Jha P, Chaloupka FJ, Chaloupka FJ, Hu TW, Warner KE, Jacobs $\mathrm{R}$, et al. The taxation of tobacco products. In: Jha $\mathrm{P}$, Chaloupka FJ eds. Tobacco control in developing countries. Oxford: Oxford University Press; 2000. p. 237-72.
39. Hu TW, Mao Z. Effects of cigarette tax on cigarette consumption and the Chinese economy. Tob control 2002;11:105-8.

40. John RM, Rao RK, Rao MG, Moore J, Deshpande RS, Sengupta J, et al. The Economics of Tobacco and Tobacco Taxation in India. Paris: International Union Against Tuberculosis and Lung Disease; 2010.

41. Laxminarayan $R$, Deolalikar A. Tobacco initiation, cessation and change: Evidence from Vietnam. Health Econ 2004; 13:1191-201.

42. Ross H, Chaloupka FJ. Economics of tobacco control. International; tobacco evidence network. 2002. Available from: http://www.tobaccoevidence.net/pdf/WEurope activites/Canarylsland_HanaandFrank.pdf [Last accessed on 2011 Jun 02].

43. Chaloupka, FJ, Hu T, Warner LE, Jacobs R, Yurekli A. The taxation of tobacco products. In: Jha $\mathrm{P}$, Chaloupka FJ, Editors, 2000: Ch 10.

44. Sunley EM, Yurekli A, Chaloupka FJ. The design, administration and potential revenue of tobacco excises. In: Jha $\mathrm{P}$, Chaloupka FJ, editors. Tobacco Control in developing countries. Oxford: Oxford University Press; 2000. p. 409-26.

45. Corrao MA, Guindon GE, Sharma N, Shokoohi DF. Editors. Tobacco Control Country Profiles. Atlanta, GA: American Cancer Society; 2000.

46. Chaloupka $F$, Jha $P$, Corrao $M$, Costa e Silva VL, Ross $H$, Czart C, et al. Smoking-Related Mortality. WHO Commission on Macroeconomics and Health Working Paper Series, June 252001.

47. International Tobacco Control Policy Evaluation Project. Available forom: http://www.itcproject.org/ [Last accessed on 2011 Nov 17].

How to cite this article: Mishra GA, Pimple SA, Shastri SS. An overview of the tobacco problem in India. Indian J Med Paediatr Oncol 2012;33:139-45.

Source of Support: Nil, Conflict of Interest: None declared.

Announcement

\section{Android App}

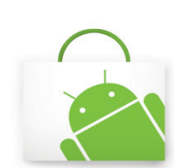
Download
Android
application

A free application to browse and search the journal's content is now available for Android based mobiles and devices. The application provides "Table of Contents" of the latest issues, which are stored on the device for future offline browsing. Internet connection is required to access the back issues and search facility. The application is compatible with all the versions of Android. The application can be downloaded from https://market.android.com/details?id=comm.app.medknow. For suggestions and comments do write back to us. 